\title{
Substrate specificity and reaction kinetics of an X-motif ribozyme
}

\author{
DENIS LAZAREV, ${ }^{1}$ IZABELA PUSKARZ, $^{2}$ and RONALD R. BREAKER ${ }^{2}$ \\ ${ }^{1}$ Department of Molecular Biophysics and Biochemistry and ${ }^{2}$ Department of Molecular, Cellular and Developmental Biology, Yale University, \\ New Haven, Connecticut 06520, USA
}

\begin{abstract}
The X-motif is an in vitro-selected ribozyme that catalyzes RNA cleavage by an internal phosphoester transfer reaction. This ribozyme class is distinguished by the fact that it emerged as the dominant clone among at least 12 different classes of ribozymes when in vitro selection was conducted to favor the isolation of high-speed catalysts. We have examined the structural and kinetic properties of the X-motif in order to provide a framework for its application as an RNA-cleaving agent and to explore how this ribozyme catalyzes phosphoester transfer with a predicted rate constant that is similar to those exhibited by the four natural self-cleaving ribozymes. The secondary structure of the X-motif includes four stem elements that form a central unpaired junction. In a bimolecular format, two of these base-paired arms define the substrate specificity of the ribozyme and can be changed to target different RNAs for cleavage. The requirements for nucleotide identity at the cleavage site are GD, where $D=G, A$, or $U$ and cleavage occurs between the two nucleotides. The ribozyme has an absolute requirement for a divalent cation cofactor and exhibits kinetic behavior that is consistent with the obligate binding of at least two metal ions.
\end{abstract}

Keywords: Engineered ribozyme; in vitro selection; mechanism; self-cleavage; transesterification

\section{INTRODUCTION}

Of the eight known natural ribozymes, four catalyze RNA cleavage by promoting internal phosphoester transfer. This RNA cleavage mechanism yields 5 '- and $3^{\prime}$-cleavage fragments with $2^{\prime}, 3^{\prime}$-cyclic phosphate and $5^{\prime}$-hydroxyl termini, respectively. These four natural self-cleaving ribozymes (McKay and Wedekind 1999; Doherty and Doudna 2000) are only a small sampling of the number of different folds that RNA can use to form an active site that promotes RNA transesterification. A number of research groups have used in vitro selection to isolate new classes of self-cleaving RNAs (Pan and Uhlenbeck 1992; Williams et al. 1995; Jayasena and Gold 1997; Tang and Breaker 1997, 2000; Salehi-Ashtiani and Szostak 2001), and these efforts have provided as many as 30 distinct classes of engineered ribozymes. Additional ribozymes that use nucleotide analogs have also been created (e.g., see Zinnen et al. 2002). These findings are consistent with the hypothesis that RNA has significant untapped potential for forming catalytic structures. Further-

Reprint requests to: Ronald R. Breaker, Department of Molecular, Cellular and Developmental Biology, Yale University, P.O. Box 208103, New Haven, CT 06520-8103, USA; e-mail: ronald.breaker@yale.edu.

Article and publication are at http://www.rnajournal.org/cgi/doi/ 10.1261/rna.2600503. more, these new ribozymes might represent prototype RNAs that can be further optimized for the efficient cleavage of specific RNA targets.

In a previous study (Tang and Breaker 2000), in vitro selection was used to isolate 12 classes of $\mathrm{Mg}^{2+}$-dependent self-cleaving ribozymes that were originally designated class I through class XII, and hereafter are termed X-motif and MR2 through MR12, respectively. As with the natural selfcleaving ribozymes, each in vitro-selected ribozyme promotes internal nucleophilic attack by the $2^{\prime}$-oxygen atom on the adjacent phosphorus center to yield $2^{\prime}, 3^{\prime}$-cyclic phosphate and $5^{\prime}$-hydroxyl termini. Interestingly, MR9 adopts the hammerhead ribozyme fold (Forster and Symons 1987) and is the only one of the 12 classes whose structure corresponds to a known natural ribozyme. Representative RNAs from the new classes exhibit rate constants that are far below those achieved by natural ribozymes, which might be indicative of the functional superiority of natural ribozymes. However, when the population was subjected to a protocol that favored the selective amplification of high-speed ribozymes, we found that a ribozyme belonging to the X-motif class supersedes the hammerhead ribozyme by achieving the best rate enhancement (Tang and Breaker 2000). Furthermore, X-motif ribozymes have an X-shaped secondary structure composed of stems I 
through IV (Fig. 1) that is amenable to rational design, such that variant ribozymes can be engineered to selectively cleave RNA targets in a sequence-specific manner. This observation confirms that new RNA-cleaving ribozymes with desirable structural and kinetic characteristics can be isolated from large random-sequence populations.

Designer substrate specificity and high catalytic rate are two features that are important for any ribozyme that is to be used as a versatile and efficient RNA-cleaving agent. Such ribozymes that could operate under physiological conditions would be attractive catalysts for the targeted destruction of cellular RNAs (Lavrovsky et al. 1997; James and Gibson 1998; Muotri et al. 1999). In this study, we have examined the sequence requirements that the X-motif ribozyme imposes on its substrates, and we have conducted a more detailed characterization of its catalytic step. We find that the substrate nucleotides required at the X-motif cleavage site are defined by the consensus GD, wherein cleavage occurs $3^{\prime}$ relative to the unpaired G residue and the flanking nucleotides are base paired with the substrate-binding arms of the ribozyme. Also, under suboptimal $\mathrm{pH}$ conditions and $\mathrm{Mg}^{2+}$ concentrations, the X-motif exhibits a rate constant of $>1 \mathrm{~min}^{-1}$. Our findings indicate that the catalytic performance of the X-motif might be improved by using in vitro selection, and that high-speed enzymes could be created for the selective cleavage of RNA under physiological conditions. Finally, we provide evidence that another class of in vitro-selected ribozymes, MR8, has some structural and functional similarities to the X-motif class of ribozymes.

Therefore, the MR8 class offers an additional candidate for optimization as high-speed RNA-cleaving ribozymes.

\section{RESULTS AND DISCUSSION}

\section{Secondary structure of X-motif ribozymes}

The initial bimolecular construct based on the X-motif ribozyme that dominates the population of in vitro-selected ribozymes described earlier (Tang and Breaker 2000) uses a 43-nucleotide catalytic domain (43X) and a separate 21nucleotide substrate RNA (S21; Fig. 1A). In our effort to confirm the secondary structure model and to create a minimal ribozyme construct, we created several shortened ribozymes that carry altered stem II sequences. For example, the artificial phylogeny that was derived by examination of numerous of X-motif variants (Tang and Breaker 2000; data not shown) reveals that this class of ribozymes tolerates sequence diversity in stem II and its adjoining loop, wherein significant base-pairing potential is maintained. This indicates that the structural integrity of stem II, but not its specific sequence, is important for ribozyme activity. To examine this hypothesis, we created a 39nucleotide ribozyme, designated 39X (Fig. 1A), and examined its RNA-cleaving activity in the presence of S21. The observed rate constant $\left(k_{\text {obs }}\right.$ ) of $\sim 0.04 \mathrm{~min}^{-1}$ measured for $39 \mathrm{X}$ approaches the $k_{\mathrm{obs}}$ value of $0.2 \mathrm{~min}^{-1}$ that is exhibited by $43 \mathrm{X}$ (Fig. 1B). In contrast, the $37 \mathrm{X}$ construct that carries a single base pair in stem II exhibits only one-hundredth the activity of $43 \mathrm{X}$ (data not shown). These findings indicate that stem II serves an important role in the active structure of $\mathrm{X}$-motif ribozymes.

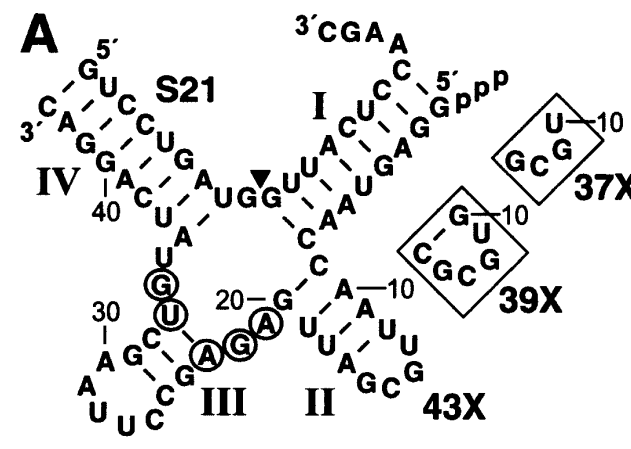

FIGURE 1. Bimolecular constructs of X-motif ribozymes. (A) Sequence and secondary-structure model of $43 \mathrm{X}, 39 \mathrm{X}$, and $37 \mathrm{X}$ in complex with the S21 substrate RNA. Roman numerals I through IV identify four putative stems that are characteristic of X-motif ribozymes. Encircled nucleotides are conserved in the ribozyme portion of all X-motif variants encountered thus far. The arrowhead identifies the site of ribozyme-catalyzed RNA cleavage. The lower and upper insets depict the shortened stem II elements that are present in $39 \mathrm{X}$ and $37 \mathrm{X}$, respectively. $(B)$ Determination of rate constants for S21 cleavage by 43X and 39X ribozymes. The fraction of S21 cleaved in the presence of $43 \mathrm{X}$ (filled circles) versus 39X (open circles) is plotted relative to incubation time, after correction for the amount of substrate that remains uncleaved on extended incubation (see Materials and Methods). Reactions contained $50 \mathrm{mM}$ Tris- $\mathrm{HCl}$ ( $\mathrm{pH} 7.5$ at $23^{\circ} \mathrm{C}$ ), $250 \mathrm{mM} \mathrm{KCl}, 20 \mathrm{mM} \mathrm{MgCl}$, trace amounts of $5^{\prime}{ }^{32} \mathrm{P}$-labeled S21, and $50 \mathrm{nM}$ of $43 \mathrm{X}$ or $39 \mathrm{X}$ RNAs. The concentration of $43 \mathrm{X}$ and $39 \mathrm{X}$ used ensures that all substrate is bound to ribozyme. The $k_{\mathrm{obs}}$ value for each ribozyme was established by determining the negative slope of the corresponding line.

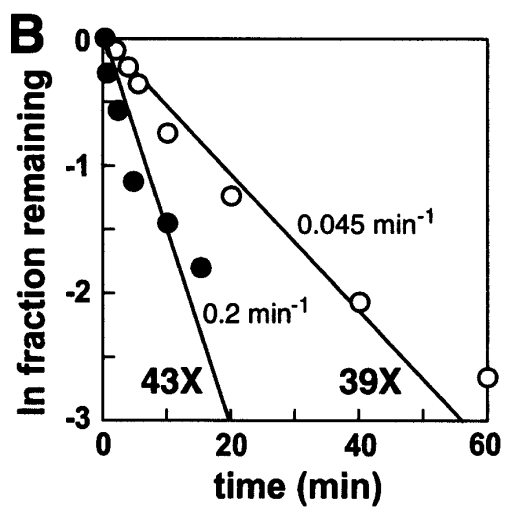

0

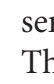

\section{hat}

tiver

\section{Sequence requirements of nucleotides near the X-motif cleavage site}

The activities of self-cleaving ribozymes are restricted to varying extents by nucleotide sequences that surround the cleavage site. For example, the hammerhead ribozyme favors cleavage between two nucleotides that conform the sequence $\mathrm{UH}$, where $\mathrm{H}$ repreA, U, or C (Hertel et al. 1992). This permits the design of different ammerhead ribozymes that can selecely cleave a wide range of RNAs that carry this consensus target sequence. revious experiments revealed that an -motif could cleave substrates whose equences differ from the original "cleavge zone" used during in vitro selection Tang and Breaker 2000). However, 
only sequences that are located some distance from the cleaved linkage were altered in the study. Therefore, we examined the sequence requirements that the ribozyme places on the single unpaired nucleotide that resides immediately $5^{\prime}$ to the target linkage, and also the two positions that flank this unpaired nucleotide.

To establish the sequence requirements for cleavage by $\mathrm{X}$-motif ribozymes, we tested a series of synthetic RNAs with single nucleotide changes relative to S21 with corresponding 39X ribozyme variants (Fig. 2). For each substrate variant, the appropriate nucleotide changes were made in the 39X ribozyme to maintain base pairing with the flanking nucleotides. The parental ribozyme exhibits substantial cleavage of the original S21 RNA, and the corresponding variant ribozymes also cleave most variant S21 RNAs that have sequence changes in the two nucleotide positions that flank the unpaired $\mathrm{G}$ residue. In contrast, any change in the nucleotide identity at the unpaired position, or an A-to-C change at the position immediately $3^{\prime}$ to the cleavage site, results in less than one-hundredth ribozyme activity compared with cleavage of the original S21 sequence. Although most substrates that differ from the original S21 sequence at positions 8 and 10 are cleaved with lesser efficiency compared with the UGG target sequence, this modest reduction in activity should not significantly restrict the utility of many engineered X-motif ribozymes. If true, then X-motif ribozymes could be used to cleave RNAs that carry a GD dinucleotide, where $\mathrm{D}$ is $\mathrm{G}, \mathrm{A}$, or $\mathrm{U}$.

\section{A consensus sequence and structural arrangement for $\mathrm{X}$-motif ribozymes}

Other critical sequence and structural elements of X-motif ribozymes were identified or are supported by examining the sequences of $>30 \mathrm{X}$-motif variants that were identified in the previous study (Tang and Breaker 2000; data not shown). For example, the existence of stem II is supported by our deletion studies described earlier, and by the observation that Watson/Crick base pairing typically is retained among variant ribozymes, despite changes in the identity of nucleotides in this region (Fig. 3). Although the first base pair relative to the central junction of stem II is either a $\mathrm{C}-\mathrm{G}$ or a $\mathrm{G}-\mathrm{C}$ interaction, this is due to the involvement of the $5^{\prime}$ primer-binding domain of the original selection construct, which is not permitted to mutate. In vitro selection gave rise to X-motif ribozymes that took advantage of one of two different fortuitous interactions between the $5^{\prime}$ primer-binding domain and the $3^{\prime}$-cleavage zone of the original construct. Therefore, all X-motif ribozymes appear to have adapted to this fortuitous interaction by forming a stem II element wherein the first base pair is restricted to the two types described earlier.

A three-base-pair element (stem III) also is predicted to form based on the conserved identities of the nucleotides involved. Although the first base pair relative to the central

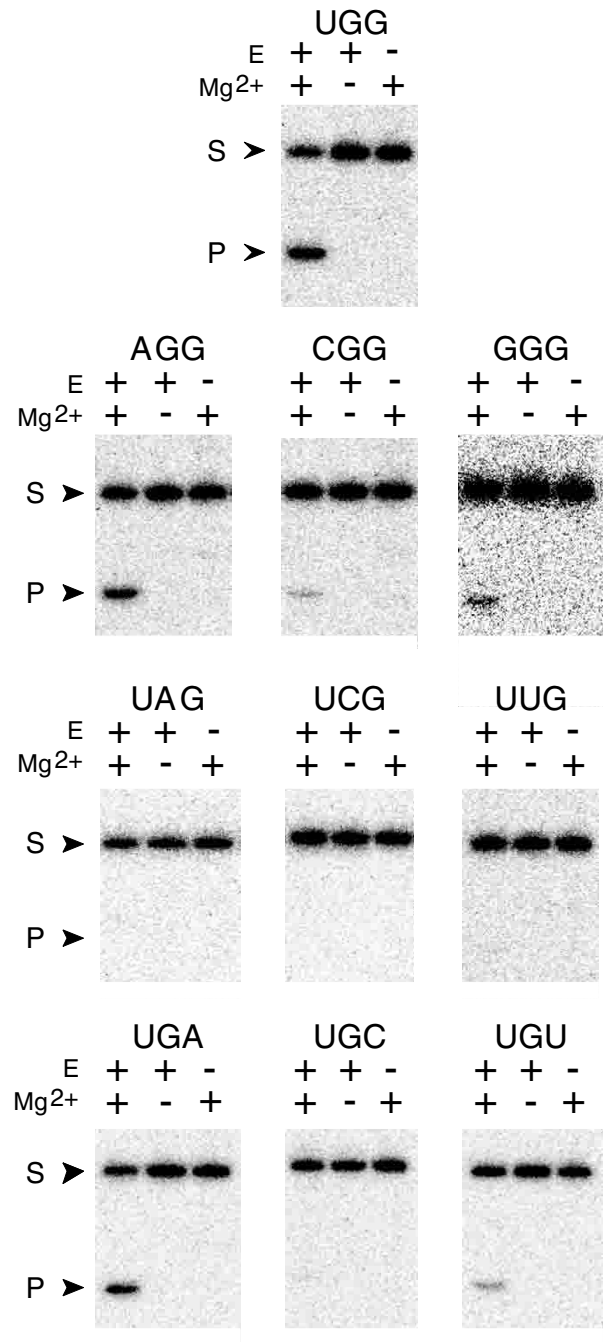

FIGURE 2. Sequence requirements for an X-motif ribozyme. The trinucleotide depicted above each panel designates the sequence of nucleotides at positions 8, 9, and 10 of each S21 substrate variant tested. The original substrate carries a UGG sequence at these positions, and the activity of the $39 \mathrm{X}$ ribozyme toward this substrate is depicted in the top panel. The activity of this ribozyme toward all possible one-nucleotide base changes relative to the UGG substrate is depicted in subsequent panels. Each assay contained a trace amount of $5^{\prime 32}$ P-labeled S21 or similarly labeled variant S21 RNA, 50 mM Tris$\mathrm{HCl}\left(\mathrm{pH} 7.5\right.$ at $\left.23^{\circ} \mathrm{C}\right)$, and $250 \mathrm{mM} \mathrm{KCl}$. The reactions were incubated at $23^{\circ} \mathrm{C}$ for $15 \mathrm{~min}$ in the absence (-) or presence (+) of $50 \mathrm{nM} \mathrm{39X}$ (E) and $20 \mathrm{mM} \mathrm{MgCl}_{2}\left(\mathrm{Mg}^{2+}\right)$, as indicated. The uncleaved substrate (S) and $5^{\prime}$-cleavage product $(\mathrm{P})$ were separated by denaturing $20 \%$ PAGE, and an autoradiogram is depicted for each analysis.

junction is always formed by A and $\mathrm{U}$ residues ( $5^{\prime}$ to $3^{\prime}$ ), base pairs 2 and 3 exhibit some variability in sequence as long as base pairing is always retained. In rare instances, the potential for four base pairs is observed in stem III, although the relative activities of these variants have not been examined. In addition, we find that two nucleotides on the loop formed by stem III are typically A residues, whereas the remainder of this loop may vary both in sequence identity and length. 


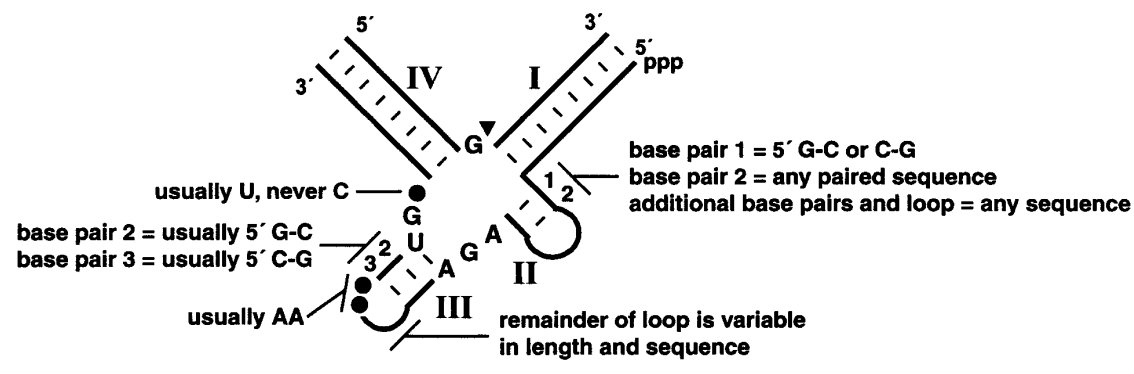

FIGURE 3. Important sequence and structural elements of X-motif ribozymes. Stems I through IV are supported by artificial phylogeny data, or have been confirmed by mutational analysis. Letters identify strictly conserved nucleotides, numbers identify conserved basepairing interactions, and filled circles identify positions that favor specific nucleotide identities, as denoted. The arrowhead indicates the site of cleavage.

Three of the four unpaired nucleotides that comprise the junction of the X-motif class of ribozymes are conserved in all variants examined. However, the unpaired residue at the base of stem IV exhibits significant variability. This position is usually occupied by a $U$ residue, and occasionally by $\mathrm{G}$ or A residues. The fact that a $\mathrm{C}$ residue is never observed in this position could reflect a disruption of the active structure that might occur if the base pairing of stem IV is extended to include the otherwise unpaired $G$ residue at the site of ribozyme cleavage.

\section{Kinetic characterization of a minimized X-motif ribozyme}

In order to characterize the X-motif class of ribozymes in greater detail, we examined several kinetic parameters of the 39X construct (Fig. 4). Specifically, we sought to examine the rate constant for the chemical step of RNA transesterification in order to make comparisons with other self-cleaving ribozymes (R.R. Breaker, G.M. Emilsson, D. Lazarev, S. Nakamura, I. Puskarz, A. Roth, and N. Sudarsan, in prep.). To this end, we used an assay strategy wherein single-turnover kinetic values for 39X function could be determined.

To ensure that the concentration of ribozyme used was sufficient to form ribozyme-substrate complexes with all 5' ${ }^{32} \mathrm{P}$-labeled S21 molecules that are present in a given reaction mixture, we determined the dependence of the rate constant for S21 cleavage on the concentration of 39X (Fig. $4 \mathrm{~A})$. The rate constant increases in proportion to the increase in concentration of $39 \mathrm{X}$, until $\sim 3 \mathrm{nM}$ of ribozyme is present. The use of $39 \mathrm{X}$ concentrations above $3 \mathrm{nM}$ does not yield higher rate constant values, indicating that the substrate is largely saturated with ribozyme at these higher concentrations. The slope of the line formed when plotting the logarithm of the rate constant versus the logarithm of the ribozyme concentration is near 1 at concentrations below saturation, which is consistent with the formation of a 1:1 complex between ribozyme and substrate. Under reaction conditions that are identical to those used for in vitro selection (Tang and Breaker 2000), the maximum $k_{\mathrm{obs}}$ for RNA cleavage by $39 \mathrm{X}$ is $0.04 \mathrm{~min}^{-1}$.

Similarly, we examined the importance of divalent and monovalent ions for X-motif ribozyme activity. The original in vitro selection from which the $\mathrm{X}$ motif was derived was conducted to favor the isolation of $\mathrm{Mg}^{2+}$-dependent ribozymes. Therefore, the resulting ribozymes are expected to require this metal ion cofactor for optimal function. Although a small fraction of the ribozyme population isolated using in vitro selection appears to function in the absence of added $\mathrm{Mg}^{2+}$ (classes not isolated; Tang and Breaker 2000), the $\mathrm{X}$-motif class of ribozymes indeed requires divalent metal ion as a cofactor (Fig. 4B). The 39X ribozyme also exhibits a striking dependency on the concentration of $\mathrm{Mg}^{2+}$, such that a 100 -fold increase in reaction rate results from each 10-fold increase in divalent ion concentration (Fig. 4B). This response to $\mathrm{Mg}^{2+}$ is consistent with the presence of at least two binding sites for $\mathrm{Mg}^{2+}$ that are critical for ribozyme function. However, the use of increasing concentrations of $\mathrm{MgCl}_{2}>200 \mathrm{mM}$ results in progressively greater ribozyme inhibition (data not shown). As a result, we could not definitively assess whether the ribozyme could be saturated with cofactor. The $39 \mathrm{X}$ ribozyme exhibits a $k_{\text {max }}$ value of $>1 \mathrm{~min}^{-1}$ under reaction conditions that are most likely suboptimal (Fig. 4B).

A mechanism for catalysis that involves a pair of coordinating divalent metal ions has been hypothesized to function in certain ribozymes (Steitz and Steitz 1993). It is possible that the active site of X-motif ribozymes carries a pair of metal ions that are positioned at the target phosphodiester linkage and that these metals could participate directly in the catalytic event. These metal ions could accelerate RNA transesterification simply by adopting inner sphere contacts with both the nonbridging phosphate oxygen and the $5^{\prime}$ (bridging) phosphate oxygen of the target linkage (Pyle 1993). In this scenario, as the $\mathrm{Mg}^{2+}$ concentration increases, the fraction of occupied metal-binding sites should undergo a corresponding rise, thereby increasing the overall number of activated ribozymes that are capable of undergoing cleavage with maximum probability. Alternatively, it is possible that the $\mathrm{Mg}^{2+}$-dependency profile of $39 \mathrm{X}$ (Fig. 4B) is due to the occupation of metal-binding sites that serve important structural roles. These metals would not directly participate in the active site of the ribozyme, but they would remain essential for the RNA to adopt its most active conformation.

Although the ribozymes were isolated in a reaction mixture that contained $250 \mathrm{mM} \mathrm{KCl}$, we find that the function of the 39X ribozyme is not affected by varying the concentration of potassium ions up to $350 \mathrm{mM}$ (Fig. 4C). Specifi- 

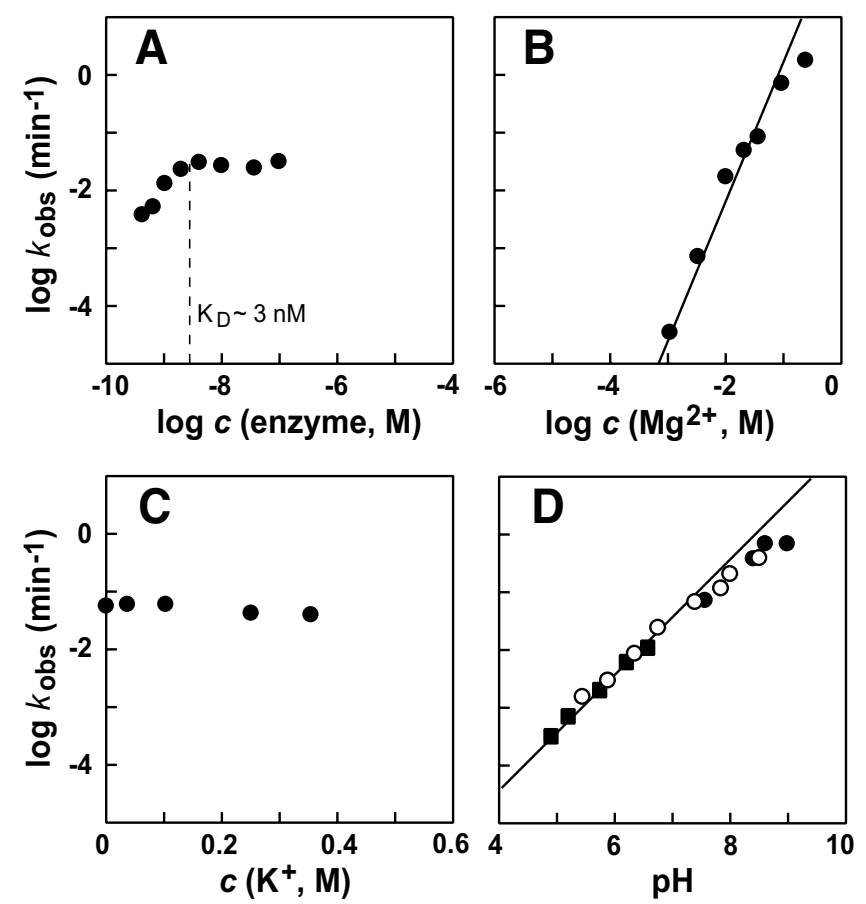

FIGURE 4. Kinetic characteristics of S21 cleavage by the 39X ribozyme. In each graph, the logarithm of the rate constant for RNA cleavage is plotted relative to the concentration of the various agents, as indicated. (A) Dependence of the rate constant on the concentration of ribozyme. Reactions contained trace amounts of $5^{\prime}{ }^{32} \mathrm{P}$-labeled $\mathrm{S} 21,50 \mathrm{mM}$ Tris- $\mathrm{HC} 1\left(\mathrm{pH} 7.5\right.$ at $\left.23^{\circ} \mathrm{C}\right), 250 \mathrm{mM} \mathrm{KCl}$, and $20 \mathrm{mM}$ $\mathrm{MgCl}_{2}$. Rate constants were determined as described in Materials and Methods. (B) Dependence of rate constant on the concentration of divalent magnesium. Reactions were conducted as described in $A$, but the concentration of $39 \mathrm{X}$ was held constant at $50 \mathrm{nM}$, and the concentration of $\mathrm{MgCl}_{2}$ was varied, as indicated. The line represents a slope of 2. (C) Dependence of rate constant on the concentration of potassium ions. Reactions were conducted as described in $B$, but the concentration of $\mathrm{MgCl}_{2}$ was held constant at $20 \mathrm{mM}$, and the concentration of $\mathrm{KCl}$ was varied, as indicated. (D) Dependence of rate constant on $\mathrm{pH}$. Reactions were conducted as described in $C$, but $\mathrm{KCl}$ was omitted from the reaction, and the $\mathrm{pH}$ was varied, as indicated. Filled circles, open circles, and filled squares identify data points generated with reactions that were buffered with Tris, HEPES, and MES, respectively. The line represents a slope of 1 .

cally, $\mathrm{K}^{+}$could be excluded from the reaction without any loss of ribozyme function, although the possible importance of trace contamination by potassium or other monovalent ions was not examined.

Finally, we examined the importance of $\mathrm{pH}$ to the activity of the 39X ribozyme. The logarithm of the rate constant for RNA cleavage increases linearly with increasing $\mathrm{pH}$ between 5 and 9 , with an apparent slope that approaches 1 . We have not examined the function of the ribozyme at $\mathrm{pH}$ values outside of the range depicted because protonation or deprotonation of nucleotide bases will cause general chemical denaturation of RNA structures that involve hydrogen bonding with base-pairing faces. Specifically, the protonation of $\mathrm{C}$ and $\mathrm{A}$ residues $\left(\mathrm{N} 3\right.$ of $\mathrm{C}, \mathrm{pK}_{\mathrm{a}} \sim 4.5$; $\mathrm{N} 1$ of $\mathrm{A}$, $\left.\mathrm{pK}_{\mathrm{a}} \sim 3.8\right)$ and the deprotonation of $\mathrm{G}$ and $\mathrm{U}$ residues
(N1 of G, $\mathrm{pK}_{\mathrm{a}} \sim 9.8$; N3 of $\mathrm{U}, \mathrm{pK}_{\mathrm{a}} \sim 10.0$ ) occur to a significant level at $\mathrm{pH}$ values below 5 and above 9, respectively (Saenger 1984). Thus, these extreme $\mathrm{pH}$ conditions are likely to destabilize Watson/Crick base-paired structures and tertiary structures that involve hydrogen-bonding contacts with these nucleotides.

The linear relationship between $\mathrm{pH}$ and the rate constant of $39 \mathrm{X}$ is consistent with a single deprotonation event that must take place in order for the substrate to be cleaved, although a more complex scenario involving multiple protonation and deprotonation events could also give rise to this $\mathrm{pH}$ profile. If the simpler model for the $\mathrm{pH}$-dependent function of $39 \mathrm{X}$ is correct, then we can also conclude that the functional group undergoing deprotonation has a $\mathrm{pK}_{\mathrm{a}}$ value that is probably $>9$. Although it is possible that this functional group is the $2^{\prime}$ hydroxyl at the site of cleavage, deprotonation could be occurring at a site that is not directly involved in the chemical step of the reaction. Thus, as might also be the case with $\mathrm{Mg}^{2+}$ interactions, deprotonation of this group might be critical for proper folding of the RNA, or for establishing a cofactor binding site.

These findings indicate that the selection conditions used to isolate the X-motif ribozymes are not optimal for $39 \mathrm{X}$ activity. By extrapolation, we had estimated that the rate constant for 39X would be $\sim 100 \mathrm{~min}^{-1}$ in the presence of $200 \mathrm{mM} \mathrm{Mg}^{2+}$ when incubated at $\mathrm{pH} 9$, assuming that no other step in the reaction pathway becomes rate limiting and that the rate enhancements observed with increasing $\mathrm{pH}$ and $\mathrm{Mg}^{2+}$ concentrations are multiplicative.

Because this projected rate constant is far too high to be measured manually using our single turnover assay strategy, we attempted to measure the maximum rate of this ribozyme under multiple turnover conditions. Unfortunately, multiple turnover ribozyme function was not observed at $23^{\circ} \mathrm{C}$, even when the incubations were conducted in the presence of $200 \mathrm{mM} \mathrm{Mg}^{2+}$ at $\mathrm{pH}$ 8.65. One possible explanation is that the rate constant for multiple turnover is limited by molecular events other than the chemical step of the reaction. Consistent with this hypothesis is the observation that higher incubation temperatures do result in multiple turnover function. For example, reactions containing Tris- $\mathrm{HCl}\left(\mathrm{pH} 8.65\right.$ at $\left.23^{\circ} \mathrm{C}\right), 200 \mathrm{mM} \mathrm{MgCl}_{2}$, and a 100 -fold excess of S21 relative to 39X resulted in $\sim 11$ turnovers in $60 \mathrm{~min}$, corresponding to a rate constant of $\sim 0.2$ $\mathrm{min}^{-1}$. A similar reaction conducted at $45^{\circ} \mathrm{C}$ resulted in $\sim 19$ turnovers in $70 \mathrm{~min}$, corresponding to a rate constant of $\sim 0.3 \mathrm{~min}^{-1}$. Because concentrations of $\mathrm{MgCl}_{2}>200 \mathrm{mM}$ increasingly cause substantial inhibition of ribozyme action, we reexamined this effect at higher $\mathrm{pH}$. We observed that high $\mathrm{MgCl}_{2}$ concentrations are even more strongly inhibitory at $\mathrm{pH}$ values near 9 (data not shown). These latter observations indicate that, although $39 \mathrm{X}$ might possess the necessary catalytic strategies to produce exceptionally highspeed catalysis, it still suffers from imperfections such as poor affinity for its cofactors and from inhibition of func- 
tion under more extreme reaction conditions. Although 39X can cleave multiple substrates under certain reaction conditions, it is likely that further structural and functional optimization of the $\mathrm{X}$-motif ribozyme is required to attain high-speed multiple turnover catalysis.

\section{The X-motif and MR8 ribozyme classes share structural and kinetic characteristics}

The MR8 class of ribozymes (Fig. 5) was derived from the same in vitro selection that produced the X-motif (Tang and Breaker 2000). To determine whether MR8 might be similar in structure and function to that of the X-motif class of ribozymes, we created a series of MR8 variants and examined the catalytic performance of each (Fig. 6). Our intention was to systematically morph the MR8 ribozyme into an X-motif ribozyme in order to determine whether the distinct structural components of each might be serving similar roles and whether these components might even be interchangeable. The ribozyme construct MR8-1 (Fig. 6A) exhibits catalytic activity that is identical to that of the original ribozyme. We then created a truncated version of MR8-1 wherein seven nucleotides of the $5^{\prime}$ terminus were replaced with a single G residue. Surprisingly, this construct (MR8-2; Fig. $6 \mathrm{~B}$ ) is rendered inactive by this deletion, indicating that the $5^{\prime}$ terminus of this ribozyme class is a critical element for catalytic function. This finding stands in contrast to the structural requirements of the X-motif class of ribozymes, which has no requirement for specific sequences in stem II or other elements that are located $5^{\prime}$ relative to this stem.

We speculated that, if MR8 ribozymes indeed are structurally related to X-motif ribozymes, then the $5^{\prime}$ unpaired element of MR8-1 might be required to compensate for the absence of a stable stem II structure. If true, then we would
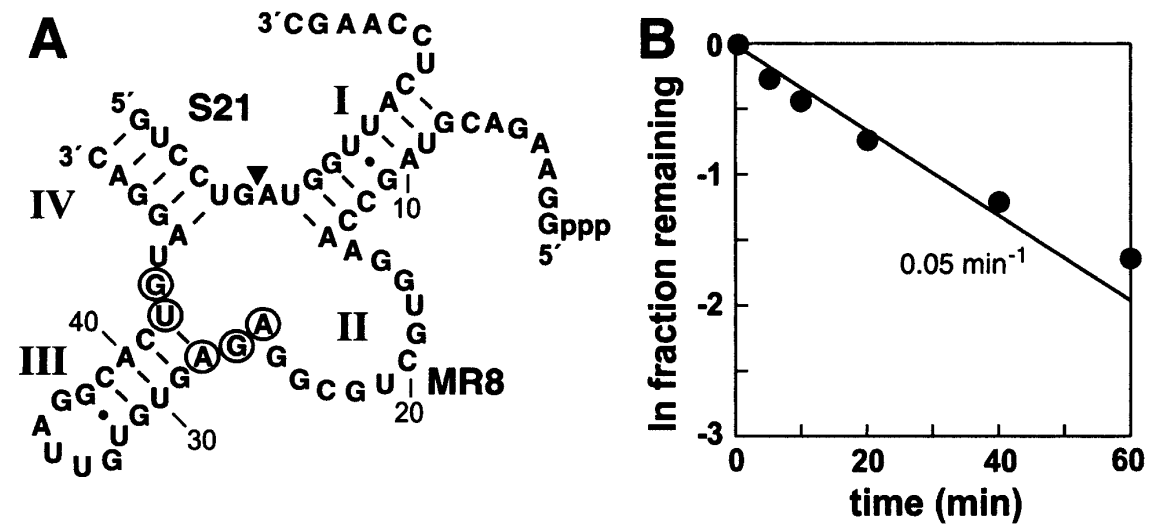

FIGURE 5. The structure and function of the MR8-1 ribozyme. (A) Sequence and secondary structure model of the MR8-1 ribozyme in complex with S21 RNA substrate. Roman numerals I through IV identify stem elements and an unstructured region (II) that correspond either in structure or in location to the four stems of X-motif ribozymes. The arrowhead identifies the site of ribozyme cleavage and encircled nucleotides match the conserved core of the X-motif ribozymes. (B) Determination of rate constant for S21 cleavage by MR8-1. The analysis was conducted as described in the legend to Figure 1B. expect that MR8-2 could be made active if the unstructured bulge was replaced by a stable stem II element. Consistent with this hypothesis is the observation that the construct MR8-3 (Fig. 6C) exhibits a modest level of RNA cleavage activity. Construct MR8-3 was created as an adaptation of construct MR8-2, wherein the unpaired bulge that is located in the stem II region was replaced by a four-base-pair hairpin element. We also examined other variants of MR8-3 wherein the nucleotide sequence and the length of stem II were altered. All exhibited a comparable level of catalytic activity (data not shown), demonstrating that the absence of the $5^{\prime}$-most nucleotides of the original MR8 sequence could be removed without loss of function if a stable stem II structure is engineered into the RNA.

Construct MR8-4 (Fig. 6D) was created to test whether a variant of the MR8-3 ribozyme with altered substrate-binding arms (stems I and IV) could be used to cleave at the same location in the S21 RNA substrate that is targeted by $\mathrm{X}$-motif ribozymes. In most respects, MR8-4 is an X-motif ribozyme with the exception of stem III, which is derived from the MR8 ribozyme. As intended, this ribozyme chimera targets the GG sequence for cleavage, and exhibits a modest level of catalytic activity.

At this stage, we attempted to combine the two alterations present in construct MR8-3 with the replacement of its original stem III element by the distinct stem III element found in the most active X-motif ribozymes. This construct, termed X-1 (Fig. 6E), essentially is an X-motif ribozyme that is targeted to cleave the internucleotide linkage of the S21 RNA substrate (the linkage formed by GA) that is normally cleaved by MR8 ribozymes. Despite the fact that the 39X ribozyme has been shown to cleave a GA target sequence with high efficiency (Fig. 2), we did not detect any cleavage by the X-1 ribozyme at this new site. However, the construct X-2 (Fig. 6F), which carries an additional three nucleotides relative to $\mathrm{X}-1$ that extend stem IV to eight base pairs, does exhibit a low level of activity. The function of X-2 on a correspondingly longer substrate RNA (S24) indicates that the different stem III elements of X-motif and MR8 ribozymes might interact differently with stem IV.

Even when taken together, these observations do not preclude the possibility that the X-motif and MR8 ribozymes are fundamentally different catalytic RNAs that tolerate significant alterations to their sequences and structures. However, the fact that several hybrid structures that represent intermediate stages of interconversion between the MR8 and X-motif structures retain high levels of RNA cleavage activity is consistent with the hypothesis that the two 

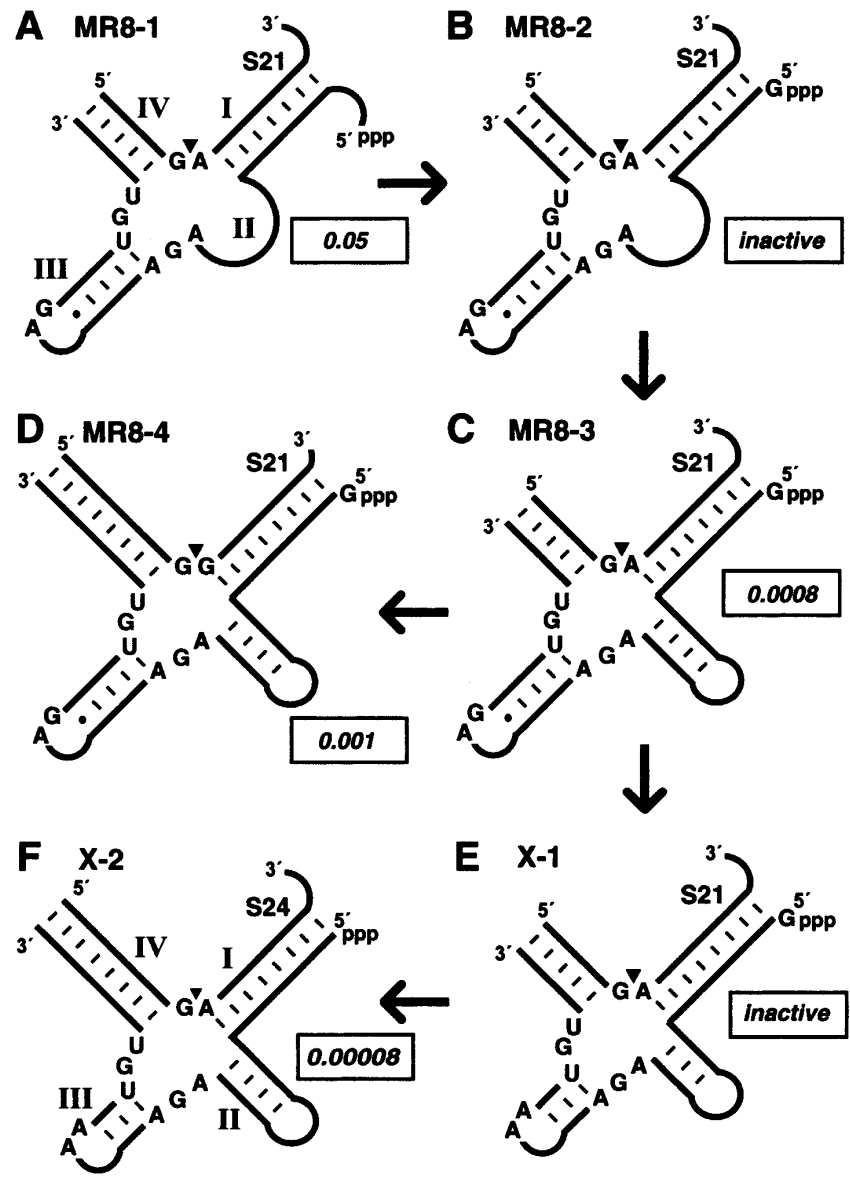

FIGURE 6. Constructs used to explore the similarity between the MR8 and X-motif classes of ribozymes. (A) The MR8-1 construct is identical to that of the MR8 sequence depicted in Figure 5A, with the exception of a single G-to-A change at position 11 that was made to establish complete Watson/Crick base pairing in stem I. (B) Construct MR8-2 is identical to MR8-1, wherein the $5^{\prime}$-most nucleotides are replaced by a single $\mathrm{G}$ residue. $(C)$ Construct MR8-3 is identical to MR8-2, wherein the 11-nucleotide internal bulge (II) is replaced by a $\mathrm{U}$ residue at position 14 and a 12-nucleotide stem-loop sequence that is identical to stem II of the $43 \mathrm{X}$ ribozyme depicted in Figure 1A. $(D)$ Construct MR8-4 is identical to MR8-3, wherein the substrate basepairing residues of stems I and IV are altered to target S21 cleavage between nucleotides 9 and 10 (the original X-motif cleavage site). (E) Construct X-1 is identical to $39 \mathrm{X}$ (Fig. 1A, inset), wherein the substrate base-pairing residues of stems I and IV are altered to target S21 cleavage between nucleotides 6 and 7 (the original MR8 cleavage site). (F) Construct X-2 is identical to construct X-1, wherein the base-pairing region of stem IV has been extended by three nucleotides to create eight base pairs with the variant substrate molecule S24. S24 is identical in sequence to $S 21$, except that three nucleotides ( $5^{\prime}$-GUC) have been added to the $5^{\prime}$ terminus. Boxed numbers represent the rate constants that were measured (MR8-1 and X-2) or that were estimated based on single-time-point assays. Rate constants $\left(\mathrm{min}^{-1}\right)$ are boxed. Constructs with undetectable levels of RNA cleavage ( $k$ values below $1 \times 10^{-5} \mathrm{~min}^{-1}$ ) are identified as inactive.

ribozymes possess similar catalytic cores. To further explore the similarities between MR8 and the X-motif class of ribozymes, we examined several kinetic parameters of MR8 function (Fig. 7) that were also determined for the 39X construct (Fig. 4). As with 39X, the activity of MR8 is in- dependent of $\mathrm{KCl}$ concentration, and the ribozyme exhibits a linear increase in activity with increasing $\mathrm{pH}$ (Fig. 7C,D). Most significantly, the catalytic activity of MR8 increases 100 -fold for each 10-fold increase in $\mathrm{Mg}^{2+}$ concentration, which is a distinguishing characteristic that is shared with $\mathrm{X}$-motif ribozymes. We find that this metal-ion dependency is rare among in vitro-selected ribozymes (data not shown). These findings are consistent with the hypothesis that the MR8 ribozyme is both a structural and functional mimic of the X-motif class of ribozymes.

\section{CONCLUSIONS}

The X-motif ribozyme is a small self-cleaving RNA that can be engineered to cleave separate RNA targets with high activity and sequence specificity. The structure is formed by a four-helix junction wherein the stem sequences can tolerate a substantial number of nucleotide changes without elimination of catalytic function. The central bulge formed by the adjoining stems carries five strictly conserved nucleotides in the ribozyme portion of the structure, and several other nucleotide positions in this putative catalytic core have preferred nucleotide identities. Although the MR8 ribozyme has several structural distinctions relative to $\mathrm{X}$ motif ribozymes (Fig. 5), our findings indicate that the two RNAs might adopt similar catalytic folds to promote substrate cleavage using similar catalytic strategies.

The kinetic characteristics of the reaction catalyzed by the
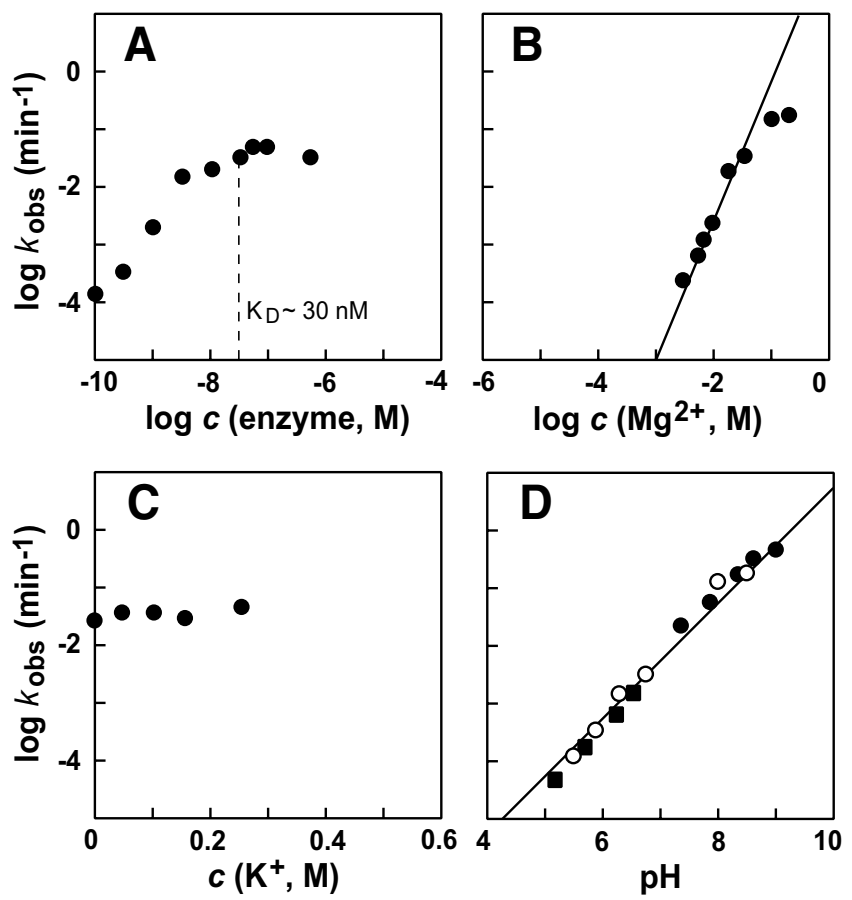

FIGURE 7. Kinetic characteristics of S21 cleavage by the MR8-1 ribozyme. Details are as described in the legend to Figure 4 except that 250 $\mathrm{mM} \mathrm{KCl}$ was present in assays that provided data for $D$. 
$\mathrm{X}$-motif and MR8 ribozymes are intriguing in several respects. First, both ribozymes appear to require at least two divalent metals as cofactors for catalytic action. The fact that neither of the two metal sites becomes convincingly saturated even when $200 \mathrm{mM} \mathrm{MgCl}_{2}$ is added to the reaction mixture implies that considerably higher rate constants for ribozyme function might be generated by optimized RNA variants that bind metal ion cofactors with higher affinity. Unfortunately, the particular version of the X-motif examined in this study shows significant inhibition of activity at higher magnesium concentrations. Second, the ribozymes exhibit a $\mathrm{pH}$ dependence that is consistent with a mechanism wherein the protonation state of a single functional group is limiting the rate constant for RNA cleavage (Figs. $4 \mathrm{D}, 7 \mathrm{D})$. Because the rate constants exhibited by both ribozymes have not reached a maximum even at $\mathrm{pH}$ values approaching 9 , it is possible that far greater rate constants might be obtained by variant ribozymes that could shift the $\mathrm{pK}_{\mathrm{a}}$ of this critical functional group. Third, the X-motif ribozyme can achieve multiple turnover, although this ability is precluded under certain reaction conditions and the rate constants for this activity are diminished under others. If each of these kinetic characteristics could be improved, for example, by additional optimization via in vitro selection, then a truly high-speed ribozyme should result. However, it is possible that overcoming limitations to the chemical step of catalysis might lead to other limiting factors such as product release. Previous efforts to create high-speed ribozymes by using in vitro selection on hammerhead (e.g., Ishizaka et al. 1995; Tang and Breaker 1997; Kore et al. 1998) or hairpin (e.g., Joseph and Burke 1993) ribozymes have not produced dramatic improvements in ribozyme catalysis; however, the X-motif architecture or that of the related MR8 ribozyme would appear to make an excellent starting point for the creation of variant ribozymes that generate rate enhancements approaching those achieved by natural protein ribonucleases (G.M. Emilsson, S. Nakamura, A. Roth, and R.R. Breaker, in prep.).

Most intriguing to us is the fact that the X-motif ribozyme must be using multiple catalytic strategies to accelerate the RNA cleavage reaction (R.R. Breaker, G.M. Emilsson, D. Lazarev, S. Nakamura, I. Puskarz, A. Roth, and N. Sudarsan, in prep.). Although defining precisely what these catalytic strategies are will require further investigation, this ribozyme can attain a rate enhancement that is as much as 500 -fold greater than the maximum rate constant that can be achieved by any enzyme that deprotonates the $2^{\prime}$-hydroxyl group to the exclusion of all other strategies ( $\mathrm{Li}$ and Breaker 1999). Moreover, the catalytic strategies that are used by X-motif and MR8 ribozymes are most likely not used to their full potential under our assay conditions.

The substrate recognition and rate enhancement characteristics of X-motif and of MR8 ribozymes are attractive for applications that require versatile and selective cleavage of RNA targets. The X-motif class of ribozymes places mini- mal restrictions on the sequence of the cleavage site. Specifically, the $\mathrm{X}$ motif requires an unpaired $\mathrm{G}$ nucleotide located $5^{\prime}$ relative to target linkage, and will tolerate any base-paired nucleotide other than $\mathrm{C}$ immediately $3^{\prime}$ of the cleavage site. These requirements are about as restrictive as those of the hammerhead ribozyme (Stage-Zimmermann and Uhlenbeck 1998), and thus the X-motif class of ribozymes appears to merit further examination as a possible platform for the design of therapeutic ribozymes.

\section{MATERIALS AND METHODS}

\section{RNA and DNA oligonucleotides}

Synthetic RNA and DNA oligonucleotides were prepared by standard solid-phase methods (Keck Biotechnology Resource Laboratory). The 2'-TBDMS groups on synthetic RNAs were removed by 24- to 30-h treatment with $1 \mathrm{M}$ tetrabutylammonium fluoride in tetrahydrofuran (THF; $\sim 150 \mu \mathrm{L}$ for each nucleotide in length). The reaction was quenched with water, and the sample was subjected to evaporation under vacuum to remove THF. The deprotected RNA was precipitated with 2.5 volumes of ethanol, and recovered by centrifugation. The dried pellet was suspended in a small volume of water and an equal volume of polyacrylamide gel electrophoresis (PAGE) loading buffer $(18 \mathrm{M}$ urea, $90 \mathrm{mM}$ Tris-borate at $\mathrm{pH} 8.0$ and $23^{\circ} \mathrm{C}, 0.6 \mathrm{M}$ sucrose, $1 \mathrm{mM}$ disodium EDTA, $0.05 \%$ $(\mathrm{w} / \mathrm{v})$ each of xylene cyanol and bromophenol blue). RNA and DNA oligonucleotides were purified by denaturing PAGE ( $8 \mathrm{M}$ urea, $89 \mathrm{mM}$ Tris-borate, $2 \mathrm{mM}$ EDTA) and isolated by crushsoaking overnight at $4^{\circ} \mathrm{C}$ in $10 \mathrm{mM}$ Tris- $\mathrm{HCl}\left(\mathrm{pH} 7.5\right.$ at $\left.23^{\circ} \mathrm{C}\right), 200$ $\mathrm{mM} \mathrm{NaCl}$, and $1 \mathrm{mM}$ EDTA. Nucleic acids were precipitated from the crush/soak solution with 2.5 volumes of ethanol, and pelleted by centrifugation. $5^{\prime}{ }_{-}^{32} \mathrm{P}$-labeled RNA molecules were prepared using T4 polynucleotide kinase (New England Biolabs) and $\left[\gamma_{-}{ }^{32} \mathrm{P}\right]$ ATP according to the manufacturer's instructions, and were purified as described earlier.

\section{Preparation of ribozyme constructs}

To generate individual ribozyme constructs with homogeneous 3' ends, double-stranded DNA templates were created using overlapping oligonucleotides. The $(-)$ oligonucleotide contained a promoter element for T7 RNA polymerase (bold), a domain that encodes the ribozyme of interest, and a domain that encodes the $5^{\prime}$ portion of the HDV ribozyme (underlined) in the following arrangement: 5'-TAATACGACTCACTATA-(ribozyme sequence)-GGCCGGCATGGTCCCAGCCTCCTCGCTG GCGC. These single-stranded (-) oligonucleotides were annealed to a $(+)$ oligonucleotide, 5'-GGTCCCATTCGCCAACCTTTCG GTTGCCCAGCCGGCGCCAGCGAGGAGGCT, that carries the 3' portion of the HDV ribozyme and a 17-nucleotide region (italics) that is complementary to the $3^{\prime}$-most region of the $(-)$ oligonucleotides. Double-stranded templates were generated using SuperScript II Reverse Transcriptase (SSRT; Gibco/BRL) by extending 200 pmole of each oligonucleotide in a $50-\mu \mathrm{L}$ reaction containing $50 \mathrm{mM}$ Tris- $\mathrm{HCl}\left(\mathrm{pH} 8.3\right.$ at $\left.23^{\circ} \mathrm{C}\right), 75 \mathrm{mM} \mathrm{KCl}, 3 \mathrm{mM}$

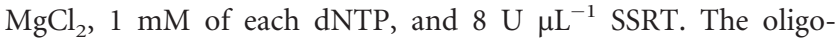
nucleotides were heated to $95^{\circ} \mathrm{C}$ for $1 \mathrm{~min}$ to disrupt any second- 
ary structure, and allowed to anneal for $5 \mathrm{~min}$ at room temperature prior to the addition of dNTPs and SSRT. The reaction was allowed to proceed for $30 \mathrm{~min}$ at $37^{\circ} \mathrm{C}$. Double-stranded DNA was recovered from the reaction mixture by precipitation with ethanol.

The DNA templates (5-50 pmole per reaction) were transcribed in a $50 \mu \mathrm{L}$ volume containing $50 \mathrm{mM}$ Tris- $\mathrm{HCl}\left(\mathrm{pH} 7.5\right.$ at $\left.23^{\circ} \mathrm{C}\right)$, $15 \mathrm{mM} \mathrm{MgCl}_{2}, 2 \mathrm{mM}$ spermidine, $5 \mathrm{mM}$ DTT, $250 \mu \mathrm{M}$ each rNTP, $40 \mu \mathrm{Ci}\left[\alpha-{ }^{32} \mathrm{P}\right]-\mathrm{UTP}$, and $8-24 \mathrm{U} \mu \mathrm{L}^{-1} \mathrm{~T} 7 \mathrm{RNA}$ polymerase. The reactions were conducted for $1-3 \mathrm{~h}$ at $37^{\circ} \mathrm{C}$, and stopped by addition of $50 \mu \mathrm{L}$ PAGE loading buffer. The design of the transcription products and the transcription reaction conditions permit the efficient self-processing of HDV ribozymes, thus yielding the desired RNA cleavage product that corresponds to the X-motif variant of appropriate length. RNA cleavage products were separated by denaturing 10\% PAGE and visualized by autoradiography or by electronic imaging (Phosphorimager, Molecular Dynamics). $\mathrm{X}$-motif ribozymes were purified from excised gel slices by crushsoaking as described earlier. Purified RNAs were quantitated using liquid scintillation counting.

\section{Kinetic assays}

\section{Single turnover assays}

In preliminary studies, we found that some ribozymes exhibited a modestly reduced rate constant ( $\sim 50 \%$ reduction) unless a preannealing protocol was used. Therefore, a general preannealing protocol was used for all experiments reported herein. In a typical experiment, a $35 \mu \mathrm{L}$ annealing mixture containing $62.5 \mathrm{mM}$ Tris$\mathrm{HCl}\left(\mathrm{pH} 7.5\right.$ at $23^{\circ} \mathrm{C}$ ), $312.5 \mathrm{mM} \mathrm{KCl}, 62.5 \mathrm{nM}$ ribozyme, and a trace amount of $5^{\prime}{ }^{32} \mathrm{P}$-labeled substrate (10 to $100 \mathrm{pM}$ ) was assembled and heated for $30 \mathrm{sec}$ at $95^{\circ} \mathrm{C}$ to disrupt any RNA aggregates. After equilibration for $10-15 \mathrm{~min}$ at $23^{\circ} \mathrm{C}$, two $16-\mu \mathrm{L}$ aliquots were withdrawn from this mixture and each added to $4 \mu \mathrm{L}$ of $100 \mathrm{mM} \mathrm{MgCl}_{2}$ to initiate two parallel reactions. This process produces a final reaction mixture containing $50 \mathrm{mM}$ Tris- $\mathrm{HCl}, 250$ $\mathrm{mM} \mathrm{KCl}, 20 \mathrm{mM} \mathrm{MgCl}_{2}, 50 \mathrm{nM}$ ribozyme, and a trace amount of substrate. The composition of the annealing mixture was altered to test different concentrations of ribozyme, $\mathrm{MgCl}_{2}, \mathrm{KCl}$, or different $\mathrm{pH}$ values.

Product yields were determined by withdrawing $2 \mu \mathrm{L}$ aliquots from each reaction and quenching with $4 \mu \mathrm{L}$ of PAGE loading buffer containing $40 \mathrm{mM}$ EDTA. The reaction products were separated by $20 \%$ PAGE and the resulting bands were visualized and quantitated by electronic imaging. The observed rate constant $\left(k_{\text {obs }}\right)$ for each assay was determined by plotting the natural logarithm of the fraction of substrate that remained uncleaved (fraction remaining) versus time. Typically, we found that no $>75 \%-$ $85 \%$ of the substrate was cleaved, even on exhaustive incubation of an assay reaction. This amount of noncleavable substrate was subtracted from the total amount of substrate added to each reaction to generate $k_{\text {obs }}$ values that more accurately reflect ribozyme function.

Mutant substrates were examined for cleavage susceptibility in reactions containing $50 \mathrm{nM}$ ribozyme and trace amounts of corresponding $5^{\prime}-{ }^{32} \mathrm{P}$-labeled substrate, $50 \mathrm{mM}$ Tris- $\mathrm{HCl}$ ( $\mathrm{pH} 7.5$ at $23^{\circ} \mathrm{C}$ ), and $20 \mathrm{mM} \mathrm{MgCl}_{2}$ using a preparative strategy similar to that described earlier. The reactions were incubated at $23^{\circ} \mathrm{C}$ for 20 min and stopped by addition of an equal volume of PAGE loading buffer containing $40 \mathrm{mM}$ EDTA. The function of MR8 and its variants was examined in a similar fashion except that $100 \mathrm{nM}$ ribozyme was used and the assays were allowed to proceed for $2 \mathrm{~h}$.

\section{Multiple turnover assays}

To determine the rate of the 39X ribozyme under multiple turnover conditions, we mixed $1 \mathrm{nM}$ ribozyme with a 100 -fold excess of substrate, or $10 \mathrm{nM}$ ribozyme with a 10 -fold excess of substrate. Phosphorylated substrates were prepared such that some molecules carry a $5^{\prime}{ }^{32} \mathrm{P}$ label. Reaction mixtures contained $50 \mathrm{mM}$ Tris- $\mathrm{HCl}\left(\mathrm{pH} 8.65\right.$ at $23^{\circ} \mathrm{C}$ ) and either 10 or $200 \mathrm{mM} \mathrm{MgCl}_{2}$, and were incubated at $23^{\circ} \mathrm{C}, 37^{\circ} \mathrm{C}$, or $45^{\circ} \mathrm{C}$ for up to $70 \mathrm{~min}$, as indicated for each experiment. To estimate the number of turnovers achieved, we multiplied the fraction of substrate cleaved as determined by electronic analysis of PAGE-separated products by the fold excess of substrate present in each reaction.

\section{ACKNOWLEDGMENTS}

We thank JoNita Kerr for her contributions to 43X data collection, and we thank other members of the Breaker laboratory members for helpful discussions and comments on the manuscript. This research was supported by a grant from Ribozyme Pharmaceuticals, Inc. R.R.B. is also supported by a fellowship from the David and Lucile Packard Foundation.

The publication costs of this article were defrayed in part by payment of page charges. This article must therefore be hereby marked "advertisement" in accordance with 18 USC section 1734 solely to indicate this fact.

Received May 10, 2002; accepted February 21, 2003.

\section{REFERENCES}

Doherty, E.A. and Doudna, J.A. 2000. Ribozyme structure and mechanisms. Annu. Rev. Biochem. 69: 597-615.

Forster, A.C. and Symons, R.H. 1987. Self-cleavage of plus and minus RNAs of a virusoid and a structural model for the active sites. Cell 49: $211-220$.

Hertel, K.J., Pardi, A., Uhlenbeck, O.C., Koizumi, M., Ohtsuka, E., Uesugi, S., Cedergren, R., Eckstein, F., Gerlach, W.L., Hodgson, R., et al. 1992. Numbering system for the hammerhead. Nucleic Acids Res. 20: 3252.

Ishizaka, M., Oshima, Y., and Tani, T. 1995. Isolation of active ribozymes from an RNA pool of random sequences using an anchored substrate RNA. Biochem. Biophys. Res. Commun. 214: 403-409.

James, H.A. and Gibson, I. 1998. The therapeutic potential of ribozymes. Blood 91: 371-382.

Jayasena, V.K. and Gold, L. 1997. In vitro selection of self-cleaving RNAs with a low pH optimum. Proc. Natl. Acad. Sci. 94: 1061210617.

Joseph, S. and Burke, J.M. 1993. Optimization of an anti-HIV hairpin ribozyme by in-vitro selection. J. Biol. Chem. 268: 24515-24518.

Kore, A.R., Heaton, P.A., Fedorova, O., and Eckstein, F. 1998. In vitro selection of a purine nucleotide-specific hammerhead-like ribozyme. Proc. Natl. Acad. Sci. 98: 2158-2162.

Lavrovsky, Y., Chen, S., and Roy, A.K. 1997. Therapeutic potential and mechanism of action of oligonucleotides and ribozymes. Biochem. Mol. Med. 62: 11-22.

Li, Y. and Breaker, R.R. 1999. Kinetics of RNA degradation by specific base catalysis involving the 2 -hydroxyl group. J. Am. Chem. Soc. 121: 5364-5372. 
McKay, D.B. and Wedekind, J.E. 1999. Small ribozymes. In The RNA world (eds. R.F. Gesteland et al.), pp. 265-286. Cold Spring Harbor Laboratory Press, Cold Spring Harbor, NY.

Muotri, A.R., Pereira, L.V., Vasques, L.R., and Menck, C.C. 1999. Ribozymes and the anti-gene therapy: How a catalytic RNA can be used to inhibit gene function. Gene 237: 303-310.

Pan, T. and Uhlenbeck, O.C. 1992. In vitro selection of RNAs that undergo autolytic cleavage with $\mathrm{Pb}^{2+}$. Biochemistry 31: 3887-3895.

Pyle, A.M. 1993. Ribozymes: A distinct class of metalloenzymes. Science 261: 709-714.

Saenger, W. 1984. Principles of nucleic acid structure. Springer-Verlag, New York.

Salehi-Ashtiani, K. and Szostak, J.W. 2001. In vitro evolution suggests multiple origins for the hammerhead ribozyme. Nature 414: 8284.
Stage-Zimmermann, T.C. and Uhlenbeck, O.C. 1998. Hammerhead ribozyme kinetics. RNA 4: 875-889.

Steitz, T.A. and Steitz, J.A. 1993. A general two-metal-ion mechanism for catalytic RNA. Proc. Natl. Acad. Sci. 90: 6498-6502.

Tang, J. and Breaker, R.R. 1997. Examination of the catalytic fitness of the hammerhead ribozyme by in vitro selection. RNA 3: 914-925.

2000. Structural diversity of self-cleaving ribozymes. Proc. Natl. Acad. Sci. 97: 5784-5789.

Williams, K.P., Ciafré, S., and Tocchini-Valentini, G.P. 1995. Selection of novel $\mathrm{Mg}^{2+}$-dependent self-cleaving ribozymes. EMBO J. 14: 4551-4557.

Zinnen S.P., Domenico, K., Wilson, M., Dickinson, B.A., Beaudry, A., Mokler, V., Daniher, A.T., Burgin, A., and Beigelman, L. 2002. Selection, design, and characterization of a new potentially therapeutic ribozyme. RNA 8: 214-228. 

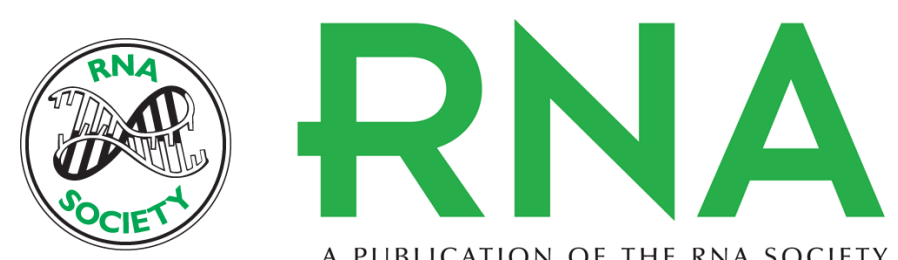

A PUBLICATION OF THE RNA SOCIETY

\title{
Substrate specificity and reaction kinetics of an X-motif ribozyme
}

\author{
DENIS LAZAREV, IZABELA PUSKARZ and RONALD R. BREAKER
}

RNA 2003 9: 688-697

References This article cites 20 articles, 9 of which can be accessed free at:

http://rnajournal.cshlp.org/content/9/6/688.full.html\#ref-list-1

\section{License}

Email Alerting Receive free email alerts when new articles cite this article - sign up in the box at the Service top right corner of the article or click here.

To subscribe to $R N A$ go to:

http://rnajournal.cshlp.org/subscriptions 